\title{
Clinico-Etiological Profile and Outcome of Children with Status Epilepticus Admitted in Pediatric Intensive Care Unit of a Tertiary Care Hospital - A Prospective Observational Study
}

\author{
M Bifina Beegum ${ }^{1}$, V K Devakumar ${ }^{2}$, Sheeja Sugunan ${ }^{3}$, Chintha Sujatha ${ }^{4}$ \\ ${ }^{1}$ MD Pediatrics, Assistant Professor, Government Medical College, Ernakulam, Kerala, India. \\ ${ }^{2}$ DNB Pediatrics, Additional Professor, SAT Hospital, Thiruvananthapuram, Kerala, India. \\ ${ }^{3}$ DNB Pediatrics, Associate Professor, SAT Hospital, Thiruvananthapuram, Kerala, India. \\ ${ }^{4}$ MD Community Medicine, Associate Professor, Government Medical College, Thiruvananthapuram, Kerala, \\ India. \\ Corresponding Author: M Bifina Beegum
}

\begin{abstract}
Objectives: We undertook this study to describe the clinical-etiological profile of children less than 12 years age with Status Epilepticus (SE) and to study the risk factors and etiologies associated with refractory status epilepticus (RSE), outcome at end of hospital stay and predictors of favourable/unfavourable outcome in SE.
\end{abstract}

Materials and Methods: Study designHospital based Prospective observational study.

Setting-Pediatric Intensive Care Unit of a tertiary care referral hospital in Kerala, India for a period of 1 year from April 2017 to April 2018.

111 children, less than 12 years age, admitted consecutively with SE were enrolled in the study. The information regarding the parameters in a structured proforma were collected by the primary investigator and entered after careful examination and appropriate investigations. Final outcome at the end of hospital stay was noted. The data collected were analyzed to identify significant factors which may predict the outcome and the risk factors associated with RSE.

Statistical Analysis: Data collected were entered in Microsoft Excel Sheet-2013.Analysis was done using Statistical Package for Social Sciences software(IBM SPSSv24).Quantitative variables were summarised as mean and $\mathrm{SD}$ and categorical variables as proportions. For testing significance of association, Chi square test was done for categorical variables and Independent T-test was done for continuous variables. $P$ value $<0.05$ was considered significant. The odds ratio with $95 \%$ confidence interval of each of the dichotomous variables by univariate analysis were determined.

Results: SE was found to be more common in 1-6 years age group followed by infancy. $51.4 \%$ of cases were boys and $48.6 \%$ were girls. Most common cause of status was febrile status followed by meningoencephalitis. Anemia was significantly associated with RSE (pvalue $=0.001$ ) and was found to be a risk factor (odds ratio=8.68). $9(8.1 \%)$ children expired. Unfavourable outcome was observed more in children who remained pain responsive or unresponsive 6 hours after seizure control, which was significant ( $p$ value $<0.01)$. Delay in initiation of first anti-epileptic drug (AED) was significantly associated with progression to RSE and unfavourable outcome.

Conclusion: We found that anemia and delay in initiation of first AED was significantly associated with RSE. There was also significant association between unfavourable outcome and children who remained pain-responsive or unresponsive 6 hours after seizure control.

Keywords- anemia, antiepileptic, febrile status, meningitis, mortality 


\section{INTRODUCTION}

Status epilepticus (SE) is the most common neurological emergency in childhood and, although treatment advances have been made, is associated with substantial morbidity and mortality ${ }^{[1,2]}$. Status cases referred to a tertiary care centre usually will reflect the severe end of the spectrum .Thus data from admissions to Pediatric Intensive Care Unit (PICU) for SE may provide some insight into determinants of severity of SE and facilitate development of appropriate strategies to reduce severity. Despite this, studies on admissions to PICU for SE in children are rare. Risk factors associated with refractory status epilepticus (RSE) are less clearly known in children. Also, most of the data about RSE is from developed countries and from epidemiological studies that included all types of SE (abortive and refractory) or combined data on adults and children ${ }^{[3,4]}$.

\section{MATERIALS AND METHODS}

We conducted a prospective observational study of all consecutive children upto 12 years of age admitted with status epilepticus in PICU of a tertiary care referral centre in Kerala, India, for a period of 1 year from April 2017 to April 2018.Newborns (less than 1 month) were excluded.

\section{Definitions}

The most widely used definition for SE was "a seizure lasting more than 30 minutes or recurrent seizures for more than 30 minutes during which the patient does not regain consciousness" $[5,6]$. More recently, an operational definition has been suggested for adults and children. In this, $\mathrm{SE}$ is defined as seizures lasting for more than 5 minutes or recurrent epileptic activity over a period of more than 5 minutes without regaining pre-existing level of consciousness $^{[7,8]}$ In our study, we used this operational definition because according to current treatment protocols, once a seizure lasts for more than five to ten minutes, it is unlikely to stop spontaneously within the next few minutes and intervention is indicated ${ }^{[1,2,7-9]}$. Also it has been found that prolonged ictal activity, whether it is associated with clinical seizures or not, causes excitatory aminoacid neurotoxicity mediated death [10]. The use of the operational definition allows early treatment (starting at 5-10 $\mathrm{min})^{[7-10]}$.

Refractory seizures are defined as seizures that persist despite the administration of two appropriate anticonvulsants (one first line eg: benzodiazepine and another antiepileptic drug) at acceptable and appropriate doses ${ }^{[7-}$ 10]. Super-refractory seizures are defined as seizures that continue 24 hours or more after the onset of anesthesia, including those cases in which the status epilepticus recurs on reduction or withdrawal of anesthesia ${ }^{[8,11]}$. Febrile status epilepticus is defined as status epilepticus in a child aged 1 month to 5 years that also meets the definition of a febrile seizure ${ }^{[12]}$.

Age group was classified into less than 1 year, 1-6 years and 6-12 years. This was done keeping in mind the higher incidence of status in infants according to literature and to compare the age group in which febrile seizures is most common (1-6 years). After careful examination and appropriate blood investigations, data were analyzed and entered. Cerebrospinal fluid (CSF) examination was done in a febrile child, after stabilizing the child and excluding raised intracranial tension. CSF examination was also done in infants less than 6 months as signs of meningitis may not be clearly demonstrated in this age group and fever also may not be present. Computed Tomography (CT) /Magnetic Resonance Imaging (MRI) were done in all cases depending on child's condition. All children with RSE were subjected to ElectroEncephaloGraphy (EEG). Sensorium was assessed based on AVPU scale (A-alert, $\mathrm{V}$-verbal, P-pain responsive, Uunresponsive).

Seizures were managed according to standard treatment guidelines ${ }^{[13]}$. 
Any complication occurring after administration of AEDs were considered as complications of drugs given. Final diagnosis and outcome at the end of hospital stay were noted.

Institutional ethical committee clearance was obtained. Informed written consent was obtained from the caretakers in English and the regional language. No additional expenses were incurred for the patient.

\section{Statistical analysis}

Data collected using the prestructured proforma were entered in Microsoft Excel Sheet-2013. Analysis was done using Statistical Package for Social Sciences software (IBM SPSSv24). Quantitative variables were summarised as mean and SD and categorical variables as proportions. For testing significance of association, Chi square test was done for categorical variables and Independent T-test was done for continuous variables. $\mathrm{P}$ value $<0.05$ was considered significant. The odds ratio with $95 \%$ confidence interval of each of the dichotomous variables by univariate analysis were determined.

\section{RESULTS}

A total of 111 children satisfying the inclusion criteria were enrolled during the study period $(n=111)$. Majority (57) of subjects $(51.4 \%)$ were boys. Minimum age studied was 9 months and maximum age was 12 years. Majority (53) of children were between 1-6 years (47.7\%) followed by infancy-44(39.6\%). Mean age was 2.9 years with standard deviation of 3.03 .

$80(72.1 \%)$ had Generalized Tonic Clonic Seizures(GTCS),21(18.9\%) had focal seizures,and10 ( $9 \%$ ) started as focal and progressed to GTCS.41(36.9\%)had past history of seizures, of which $20(48.8 \%)$ were febrile and 21(51.2\%) afebrile.61(54.9\%) of the total 111 subjects had family history of seizures, of which majority $47(77 \%)$ had family history of febrile seizures.80 children(72\%) were referred from various primary and secondary care hospitals, both from government and private sector.75(93.8\%) of the children who were referred had been given 1st dose of AED from referring hospital.

81 cases of status were refractory (72.9\% of total), and 5 cases were super refractory ( $4.5 \%$ of total). Refractory status was more common in boys, with age group upto 6 years but the association was not significant ( $\mathrm{p}$-value $=0.304$ ).

Investigations done are summarized in Table 1. We also found that there is no significant association of refractory status with history of birth asphyxia, development delay, past history or family history of seizures, raised C-Reactive Protein (CRP) or abnormal brain imaging (Table 2)

Sensorium was assessed based on AVPU scale. Six hours after seizure control, majority of children 53(47.7\%) became verbal, $17(15.3 \%)$ became alert,39(35.1\%) remained pain responsive and $2(1.8 \%)$ remained unresponsive.

We found significant association between anemia and refractory status ( $p$ value $=0.001$ ) and anemia was found to be risk factor for status becoming refractory (odds ratio $=8.68$ ) (Table 2)

Raised CRP was significantly associated with meningitis than febrile status ( $p$ value $=0.07)$ (Table 3).

EEG was done for 105(94.5\%) children with status. This included all children with RSE. In some cases, EEG could be done only after status was controlled. $35(83.3 \%)$ of children with abnormal EEG had refractory status and the $\mathrm{p}$ value $=0.05$.

MRI abnormalities detected were cortical hyperintensities seen in 12 children with meningoencephalitis (including 2 with Herpes Simplex Virus (HSV) encephalitis, while other children with Central Nervous System (CNS) infections had normal brain imaging.

Regarding final diagnosis, majority$51(45.9 \%)$ had febrile status followed by meningoencephalitis- 24(21.6\%). Most common etiology in RSE also came out to 
M Bifina Beegum et.al. Clinico-etiological profile and outcome of children with status epilepticus admitted in pediatric intensive care unit of a tertiary care hospital - a prospective observational study.

be febrile status 35(43.2 \% of RSE) followed by meningoencephalitis-20 ((24.6\% of RSE). 2 children had HSV encephalitis, 8 had CSF culture proven meningitis and others had presumed encephalitis. Autoimmune encephalitis and intracranial bleed were the least common causes. The other causes for status in our study are enumerated in Figure 1.

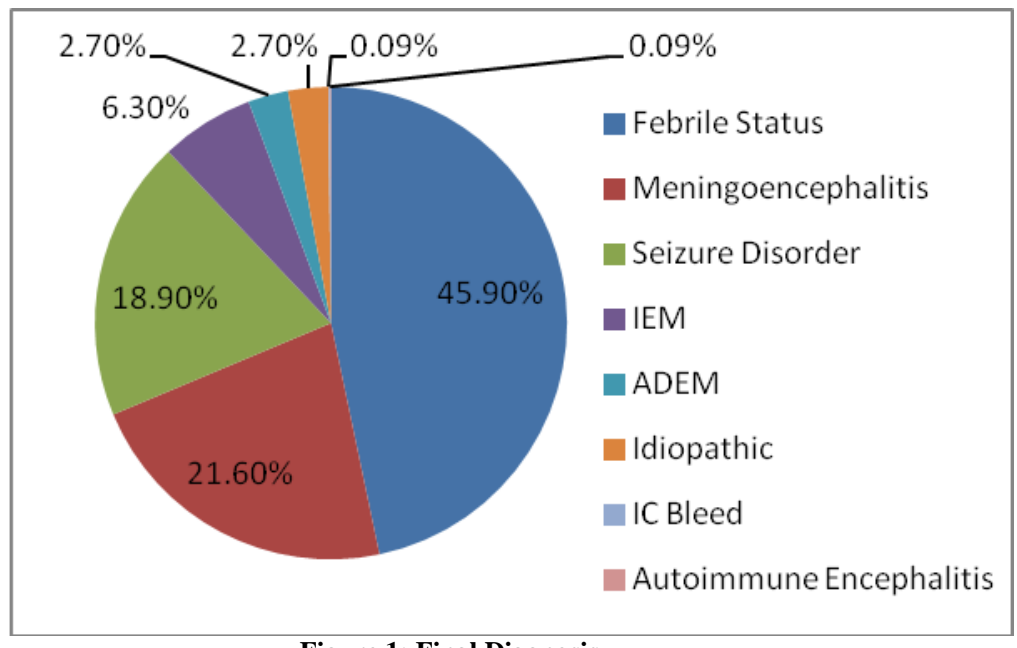

Figure 1: Final Diagnosis

Table 1: Laboratory profile of children with Status Epilepticus

\begin{tabular}{|c|c|c|}
\hline & No of Cases(n) & Proportion of Cases (\%) \\
\hline Anemia* (WHO Criteria) & 33 & 29.7 \\
\hline Leucocytosis $\left(\mathrm{TC}^{\#}>11 \times 10^{3} / \mathrm{L}\right)$ & 44 & 39.6 \\
\hline Leucopenia $\left(\mathrm{TC}^{\#}<4 \times 10^{3} / \mathrm{L}\right)$ & 7 & 6.3 \\
\hline Thrombocytopenia $^{\$}$ & 7 & 6.3 \\
\hline $\mathrm{CRP}^{\wedge}>0.6 \mathrm{Mg} / \mathrm{dl}$ & 37 & 33.3 \\
\hline Hypoglycemia $\left(\mathrm{RBS}^{\mp}<54 \mathrm{mg} / \mathrm{dl}\right)$ & 6 & 5.4 \\
\hline Hyperglycemia $\left(\mathrm{RBS}^{\mp}>180 \mathrm{mg} / \mathrm{dl}\right)$ & 2 & 1.8 \\
\hline Hypocalcemia (Corrected $\mathrm{Ca}<8.4 \mathrm{mg} / \mathrm{dl})$ & 2 & 1.8 \\
\hline Hyponatremia** & 12 & 10.8 \\
\hline Hypomagnesemia $(\mathrm{Mg}<1.5 \mathrm{mg} / \mathrm{dl})$ & 0 & 0 \\
\hline Acute Kidney Injury $^{\# \#}$ & 6 & 5.4 \\
\hline Abnormal liver function tests ${ }^{\$ \$}$ & 8 & 7.8 \\
\hline $\mathrm{INR}^{\wedge \wedge}>1.5$ & 8 & 7.8 \\
\hline Abnormal Brain Imaging & 30 & 29.7 \\
\hline Abnormal EEG & 42 & 37.8 \\
\hline
\end{tabular}

*WHO cut-off for anemia in different age groups; \#TC:Total count; \$Platelet count $<1$ lakh/cu mm; ${ }^{\wedge}$ C-Reactive protein; $\neq$ Random Blood sugar $<54 \mathrm{mg} / \mathrm{dL} ; * *$ Hyponatremia was reported as normal or abnormal based on the age-related normal range: $<1$ year $-130-145 ;>1$ year -137 -145; \#\#Acute kidney injury-based on pRIFLE criteria-all children satisfying criteria starting from risk according to the classification was grouped as having acute kidney injury [13]; \$\$Liver function tests-reported based on age related standards of SGOT and SGPT and reported as abnormal if result more than 3 times baseline $[14] ;{ }^{\wedge}$ INR $>1.5$

Table 2: Factors associated with refractory status, including final outcome at discharge

\begin{tabular}{|c|c|c|c|c|c|}
\hline \multicolumn{2}{|l|}{ Variable } & $\begin{array}{l}\text { Refractory } \\
n(\%)\end{array}$ & $\begin{array}{l}\text { Non refractory } \\
n(\%)\end{array}$ & Pvalue $*$ & Odds ratio $(95 \%$ CI) \\
\hline \multirow[t]{2}{*}{ Gender } & Boys & $44(77.2)$ & $13(22.8)$ & \multirow[t]{2}{*}{0.304} & \multirow[t]{2}{*}{$1.555(0.669-3.617)$} \\
\hline & Girls & $37(68.5)$ & $17(31.5)$ & & \\
\hline \multirow{2}{*}{ Age group } & $1 \mathrm{yr}$ to $6 \mathrm{yrs}$ & $37(69.8 \%)$ & $16(30.1 \%)$ & \multirow{2}{*}{0.15} & \\
\hline & $6 \mathrm{yrs}$ to $12 \mathrm{yrs}$ & $8(57.1 \%)$ & $6(42.8 \%)$ & & \\
\hline \multirow[t]{2}{*}{ Anaemia } & Present & $31(93.9 \%)$ & $2(6.1 \%)$ & \multirow[t]{2}{*}{0.001} & \multirow[t]{2}{*}{$8.68(1.93-39.014)$} \\
\hline & Absent & $50(64.1 \%)$ & $28(35.9 \%)$ & & \\
\hline \multirow[t]{2}{*}{ CRP } & Raised CRP & $31(83.8)$ & $6(16.2)$ & \multirow[t]{2}{*}{0.07} & \multirow[t]{2}{*}{$2.48(0.224-1.116)$} \\
\hline & Normal CRP & $50(67.6)$ & $24(32.4)$ & & \\
\hline \multirow[t]{2}{*}{ Brain Imaging } & Abnormal & $24(80 \%)$ & $6(20 \%)$ & \multirow[t]{2}{*}{0.391} & \multirow[t]{2}{*}{$1.569(0.558-4.408)$} \\
\hline & Normal & $51(71.8 \%)$ & $20(28.2 \%)$ & & \\
\hline Final outcome & Favourable outcome & $60(68.9 \%)$ & $27(31.03 \%)$ & & \\
\hline
\end{tabular}


M Bifina Beegum et.al. Clinico-etiological profile and outcome of children with status epilepticus admitted in pediatric intensive care unit of a tertiary care hospital - a prospective observational study.

\begin{tabular}{|c|c|c|c|c|}
\hline \multicolumn{5}{|c|}{ Table 3:Distribution of raised CRP( C-Reactive Protein) with febrile status and meningoencephalitis } \\
\hline & Febrile status & Meningitis & Total & CHI SQUARE=21.795 \\
\hline Raised CRP & $8(16 \%)$ & $17(70.8 \%)$ & 25 & PVALUE $<0.01$ \\
\hline Normal CRP & $42(84 \%)$ & $7(29.2 \%)$ & 49 & ODDS RATIO $=0.078$ \\
\hline Total & $50(100 \%)$ & $24(100 \%)$ & 74 & $95 \% \mathrm{CI}=0.025$ TO 0.25 \\
\hline
\end{tabular}

Table 4: Association between Delay in receiving $1^{\text {st }}$ AED, refractory status,and outcome at discharge

\begin{tabular}{|l|l|l|c|c|}
\hline & $\begin{array}{l}\text { Duration of seizures before } \boldsymbol{1}^{\text {st }} \\
\text { AED Less than 30 minutes }\end{array}$ & $\begin{array}{l}\text { Duration of seizures before } \mathbf{1}^{\text {st }} \text { AED } \\
\text { More than 30 minutes }\end{array}$ & CHISQUARE & P VALUE \\
\hline Refractory status & $63(69.2 \%)$ & $18(90 \%)$ & 3.58 & \\
\hline Nonrefractory status & $28(30.7 \%)$ & $2(10 \%)$ & & \\
\hline Favourable outcome & $75(82.4 \%)$ & $12(60 \%)$ & & \\
\hline Unfavourable outcome & $16(17.5 \%)$ & $8(40 \%)$ & 4.05 \\
\hline
\end{tabular}

$25(22.5 \%) \quad$ children required mechanical ventilation during PICU stay.

At discharge, the children were grouped into those having favourable outcome (returned to normal or previous baseline) and those with unfavourable outcome (new FND or death). We found that $87(78.4 \%)$ had favourable outcome while $24(21.6 \%)$ had unfavourable outcome. Mortality rate was $9(8.1 \%)$.

Unfavourable outcome was more commonly associated with those children who remained pain responsive or unresponsive $6 \mathrm{hrs}$ after seizure control. This association was significant ( $p$ value $<0.01)$. Also, more children with unfavourable outcome (21 out of 24 ie $87.5 \%$ ) had refractory status than children with favourable outcome (60 out of 87 ie $68.9 \%)(\mathrm{p}$ value $=0.07)$.

Diazepam was the most common 1st AED given, before referral. Diazepam was used in 54(48.6\%) subjects and lorazepam was used in 51(45.9\%) subjects with only $3(2.7 \%)$ using midazolam as 1st AED. Lorazepam was the most common $1^{\text {st }}$ AED given from the centre of study. $2^{\text {nd }}$ AED given from centre of study was fosphenytoin followed by levetiracetam. Of the children with refractory status, maximum- 54 of 81(66.6\%) were controlled with levetiracetam. Other AEDs which were used in our PICU were Phenobarbitone, Valproate, Thiopentone, Midazolam infusion and Lacosamide. Maximum number of AEDs for seizure control was 9 drugs used for 1 child with idiopathic cause.
63 of 91(69.2\%) children who received $1^{\text {st }}$ AED early (within 30 min of seizures) had refractory seizures and 16 of them $(17.5 \%)$ had unfavourable outcome at discharge. In contrast, 18 of 20 (90\%) who received $1^{\text {st }}$ AED late (after 30 minutes) had refractory seizures ( $\mathrm{p}$ value $=0.05$ ) and 8 of $20(40 \%)$ had unfavourable outcome at discharge (p value $=0.02) \quad$ (Table 2). Duration between $1^{\text {st }}$ and $2^{\text {nd }}$ AED was not found to significantly affect refractoriness (p value 0.07 )

\section{DISCUSSION}

Of the 111 children with status epilepticus we studied, majority $(51.4 \%)$ were boys.1-6 years age group (47.7\%) was found to be maximum(47.7\%) affected followed by infancy(39.6). Various literature shows that incidence of convulsive status epilepticus is highest in younger age groups, which could be due to increased incidence of acute symptomatic causes in very young age group and also due to vulnerability for seizures in the immature brain. ${ }^{[16,17]}$

More than $90 \%$ subjects belonged to lower socioeconomic group, which may be due to the fact that the centre of study provides free care to children under various schemes sanctioned by the government. $72 \%$ of children were referred from other peripheral hospitals. Except $5(6.2 \%)$ of the referred children, others (93.8\%) had been referred after administration of 1st AED.

Majority $(72.9 \%)$ of children in our study progressed to RSE. This may be because of the fact that duration of seizures was not considered to define RSE in our 
study. A two year multi-centre study done in U.K. (Tully et al) used the same definition for refractory status as we used ${ }^{[18]}$. In studies where definition of RSE had an additional criteria of lasting longer than 60 minutes, percentage of children classified as RSE was less. ${ }^{[19]}$

The most common cause of status in our study was febrile status (45.9\%) followed by meningoencephalitis (21.6\%). Most common etiology in RSE also came out to be febrile status followed by meningoencephalitis. In literature also, concordant with our study, most common cause of status epilepticus in children, especially less than 6 years age, is found to be febrile status. Younger children are more prone for febrile status and acute symptomatic etiology while older children are more likely to have remote or cryptogenic causes ${ }^{[16,18]}$. In some studies, children with febrile status were included in the acute symptomatic group while in some other studies, these children were analysed separately because of lack of direct CNS involvement in febrile seizures ${ }^{[20]}$.

As found in our study, evidence from literature shows that children with refractory status had more unfavourable outcome and mortality than those with abortive status [20,21]. We also found that unfavourable outcome was more commonly associated with those children who remained pain responsive or unresponsive $6 \mathrm{hrs}$ after seizure control. This association was significant ( $\mathrm{p}$ value<0.01). More studies are warranted to use this as a criteria for predicting unfavourable outcome in status epilepticus.

We found that, though majority of our children had received $1^{\text {st }}$ AED from referral centre, delay in receiving the $1^{\text {st }}$ AED significantly caused refractory seizures and unfavourable outcome at discharge. This delay was in majority of cases the time taken in travelling the distance from the patient's homes to the nearest health care facility and then to our hospital. According to various literature, timely administration of AED from referring centre and thus avoiding delay in initiation of treatment significantly improved outcome [20,21]. Suboptimally organized pre-hospital services greatly affect the evaluation, management and transport of the acutely ill child to an appropriate facility ${ }^{[19-21]}$.

We found that there is significant association between anemia (in $93.9 \%$ ) and refractory status. Anemia was found to be risk factor for status becoming refractory (odds ratio $=8.68$ ).

We also found that raised CRP was significantly associated with meningitis $(70.8 \%)$ than febrile status $(16 \%)(\mathrm{p}$ value $<0.01$.). Other studies on RSE have not explored these parameters in blood investigations and more studies are required to validate the same.

Mortality was 9(8.1\%). Previous studies have reported mortality rates of 12 $32 \%{ }^{[17,20]}$. Lower mortality rates have been reported in studies done, predominantly in western population ${ }^{[22]}$. This difference in mortality could be due to the fact that in developing countries, children referred to tertiary centres have very severe/prolonged seizures, where initial management strategies tried at primary and secondary centres have failed. Also children in developing countries are at higher risk of acute symptomatic causes like CNS infections and these are associated with higher mortality. These children also have more complications during their delay in initiation of treatment ${ }^{[19-21]}$

$83.3 \%$ of children with abnormal EEG had refractory status and the $\mathrm{p}$ value $=0.05$.

Not many studies on usefulness of EEG in pediatric SE are available. EEG abnormalities have been reported in $\sim 90 \%$ children presenting with seizures, though these were done hours to days later ${ }^{[23] .}$ The information whether the seizure is focal or generalized is an important one when deciding chronic AED therapy for the patient. After convulsive seizures, one-third of children who undergo EEG monitoring are reported to have electrographic seizures, and among these, one-third experience entirely electrographic-only seizures ${ }^{\text {[24]. }}$ 
Continuous EEG monitoring was not available in our centre.

\section{CONCLUSION}

- There is no significant association of refractory status with history of birth asphyxia, developmental delay, past history or family history of seizures, raised CRP or abnormal brain imaging.

- Most common cause of SE and RSE was febrile status followed by meningoencephalitis.

- Delay in initiation of first anti-epileptic drug was significantly associated with progression to refractory status and later unfavourable outcome. This was mainly due to time taken by the patient to reach the nearest health centre, which lends great importance in strengthening the prehospital care and first aid measures.

- Anemia was significantly associated with refractory status ( $p$ value $=0.001$ ) and was found to be a risk factor (odds ratio $=8.68$ )

- Unfavourable outcome was more commonly associated with those children who remained pain responsive or unresponsive $6 \mathrm{hrs}$ after seizure control. This association was significant ( $\mathrm{p}$ value $<0.01$ )

\section{Acknowledgement: None}

\section{Conflict of Interest: None}

\section{Source of Funding: None}

Ethical Approval: Ethical committee clearance given by Institutional ethical committee/Human Ethics Committee, Medical College, Thiruvananthapuram. (IEC.No.01/21/2017/MCT dated 06/01/2017)

\section{REFERENCES}

1. Pellock jm. Status epilepticus in children: update and review. $J$ child neurol. 1994;9:27-35.
2. Lowenstein dh, bleck t, macdonald rl. It's time to revise the definition of status epilepticus. Epilepsia. 1999; 40:120-2.

3. Chin $\mathrm{rfm}$, verhulst 1 , neville bgr, peters mj, scott rc. Inappropriate emergency management of status epilepticus in children contributes to need for intensive care. J neurolneurosurg psychiatry $2004 ; 75$ : $1584-$ 88.

4. Owens j. Medical management of refractory status epilepticus. Seminpediatr neurol. 2010;17:176-81.

5. Epilepsy foundation of america's working group on status epilepticus. Treatment of convulsive status epilepticus. Recommendations of the epilepsy foundation of america's working group on status epilepticus. J am med assoc. 1993; 270:854-59.

6. Commission on epidemiology and prognosis, international league against epilepsy. Guidelines for epidemiologic studies on epilepsy. Epilepsia. 1993;34:59296.

7. Raj D, Gulati S, Lodha R. Status epilepticus. Indian J Pediatr. 2011 Feb;78(2):219-26.

8. Mohamad A. Mikati, Abeer J. Hani. Seizures in Childhood .In:Kliegman,St Geme,Blum,Shah,Tasker,Wilson,eds.Nelson Textbook Pediatrics.Philadelphia:Elsevier:2016: $.20^{\text {th }}$ ed .p.2823-2856

9. Shinnar s, berg at, moshe sl, shinnar r. How long do new-onset seizures in children last? Ann neurol. 2001; 49:659-64.

10. Capovilla g, beccaria $f$, beghi e, minicucci $f$, sartori s, vecchi m. Treatment of convulsive status epilepticus in childhood: recommendations of the italian league against epilepsy. Epilepsia. 2013;54:23-34.

11. Ferlisi m, shorvon s. The outcome of therapies in refractory and super-refractory convulsive status epilepticus and recommendations for therapy. Brain. 2012;135:2314-28.

12. Hesdorffer Dc, Shinnar S, Lewis Dv, Nordli Dr, Pellock Jm, Moshe et al. For the febstat study team. Risk factors for febrile status epilepticus: a case-control study. J pediatr. 2013;163:1147-51.

13. Glauser, T., Shinnar, S., Gloss, D., Alldredge, B., Arya, R., Bainbridge, J., Bare, M., Bleck, T., Dodson, W. E., Garrity, L., Jagoda, A., Lowenstein, D., Pellock, J., 
Riviello, J., Sloan, E., \& Treiman, D. M. (2016). Evidence-Based Guideline: Treatment of Convulsive Status Epilepticus in Children and Adults: Report of the Guideline Committee of the American Epilepsy Society. Epilepsy Currents, 16(1), 48-61. https://doi.org/10.5698/1535-759716.1.48

14. Bresolin N, Bianchini AP, Haas CA. Pediatric acute kidney injury assessed by pRIFLE as a prognostic factor in the intensive care unit. Pediatr Nephrol. 2013 Mar;28(3):485-92. doi: 10.1007/s00467012-2357-8. Epub 2012 Nov 24.

15. Bain BJ, Bates I, Laffan MA, Lewis SM, editors. Dacie and Lewis Practical Haematology.Pathology,12th edition.Philadelphia,PA;Elsevier:2016

16. Gulati s, Raspall-chaure $\mathrm{m}$, chin $\mathrm{r}$, neville $\mathrm{b}$, bedford $h$, scott $r$. The epidemiology of convulsive status epilepticus in children: a critical review. Epilepsia. 2007;48(9):16521663.

17. kalra $\mathrm{v}$, sridhar $\mathrm{m}$. Status epilepticus in indian children in a tertiary care center. The indian journal of pediatrics. 2005;72(2):105108.

18. Tully i, draper e, lamming c, mattison d, thomas c, martland t et al. Admissions to paediatric intensive care units (picu) with refractory convulsive status epilepticus (rcse): a two-year multi-centre study. Seizure. 2015;29:153-161.

19. Mayer SA, Claassen J, Lokin J, Mendelsohn F, Dennis LJ, Fitzsimmons BF. Refractory status epilepticus: frequency, risk factors, and impact on outcome. Arch Neurol. 2002 Feb;59(2):205-10. 10.1001/archneur.59.2.205.
20. Lingappa 1, konanki r, patel r, vooturi s, jayalakshmi s. Clinical profile and outcome of refractory convulsive status epilepticus in older children from a developing country. Seizure. 2016;36:31-35.

21. Santhanam i, yoganathan s, sivakumar v, ramakrishnamurugan $r$, sathish $\mathrm{s}$, thandavarayan $\mathrm{m}$. Predictors of outcome in children with status epilepticus during resuscitation in pediatric emergency department: a retrospective observational study. Annals of indian academy of neurology. 2017;20(2):142..

22. Pascual-Castroviejo I, Martínez-Bermejo A, Pascual-Pascual SI. Status epilepticus en la infancia [Status epilepticus in childhood]. Neurologia. 1997 Dec;12 Suppl 6:38-45. Spanish.

23. Tay SK, Hirsch LJ, Leary L, Jette N, Wittman J, Akman CI. Nonconvulsive status epilepticus in children: clinical and EEG characteristics. Epilepsia. 2006 Sep;47(9):1504-9. doi: 10.1111/j.15281167.2006.00623.x.

24. Yuliati A, Weber ARB. Use of Continuous EEG Monitoring in Children Presenting With Encephalopathy Following Convulsive Status Epilepticus. J Clin Neurophysiol. 2019 May;36(3):181-185. doi: 10.1097/WNP.0000000000000566.

How to cite this article: M Bifina Beegum, Devakumar VK, Sugunan S et.al. Clinicoetiological profile and outcome of children with status epilepticus admitted in pediatric intensive care unit of a tertiary care hospital - a prospective observational study. International Journal of Research and Review. 2021; 8(7): 473-480. DOI: https://doi.org/10.52403/ijrr. 20210767 